\title{
CLIMA URBANO ATRAVÉS DE SENSORIAMENTO REMOTO: EVOLUÇÃO HISTÓRICA DA TERMOGRAFIA DA SUPERFÍCIE DE PARANAVAÍ/PR - BRASIL
}

\author{
Larissa PifferDorigon $^{(a)}$, Margarete Cristiane de Costa Trindade Amorim ${ }^{\text {(b) }}$ \\ (a) Departamento de Geografia, Faculdade de Ciências e Tecnologia, campus de Presidente Prudente, \\ laridorigon@hotmail.com. \\ (b) Departamento de Geografia, Faculdade de Ciências e Tecnologia, campus de Presidente Prudente, \\ mccta@fct.unesp.br.
}

\section{Eixo: Climatologia em diferentes níveis escalares: mudanças e variabilidades}

\begin{abstract}
Resumo
O desenvolvimento e aprimoramento das técnicas de sensoriamento remoto vêm sendo essenciais nos estudos sobre clima urbano, pois proporcionam comparações ao longo do tempo. Neste sentido, o objetivo principal deste artigo foi identificar a influência exercida pelos diferentes usos e coberturas da terra, ao longo dos anos, na estrutura térmica da superfície urbana de Paranavaí. Utilizaram-se imagens remotas dos satélites Landsat 7 e 8, que permitiram a análise histórica dos anos de 2002 e 2014. Iniciou-se com o pré-processamento (correção atmosférica) e então, partiu-se para o processamento completo. As cartas elaboradas foram as de temperatura da superfície, NDVI e uso e cobertura da terra. Como principais resultados detectou-se que a substituição de vegetação por materiais construtivos elevaram a temperatura da superfície, que a vegetação mostrou-se fundamental na diminuição ou amenização destas temperaturas e que o sensoriamento remoto é uma ferramenta muito útil aos estudos de clima urbano e deve ser explorado.
\end{abstract}

Palavras chave: Clima urbano, temperatura da superfície, NDVI, uso e cobertura da terra, Paranavaí/PR.

\section{INTRODUÇÃO}

As cidades ganham cada vez mais habitantes e se constituem no principal modo de vida humana, devido à concentração de atividades e serviços nelas encontradas. Esse processo leva a radical transformação da paisagem natural dentro dos centros urbanos que não se limita a causar impactos na morfologia do terreno no qual estão inseridas, mas também modificam as condições ambientais e climáticas, dando origem a um ambiente eminentemente antropizado, no qual a geração de um clima específico para cada local pode ser um exemplo destas ações.

Aspectos como rugosidade, retirada de vegetação arbórea, densidade de construções e edificações e a geometria do traçado urbano, além das funções econômicas e sociais desenvolvidas no local, podem ser fatores determinantes na geração de um clima das cidades, uma vez que modificam as trocas padrões de energia entre a superfície e a atmosfera, afetando assim, o funcionamento dos componentes climáticos, condicionando o que se denomina de clima urbano (AMORIM, 2000). 


\section{OS DESAFIOS DA GEOGRAFIA FÍSICA NA FRONTEIRA DO CONHECIMENTO \\ Instituto de Geociências - Unicamp \\ Campinas - SP \\ 28 de Junho à 02 de Julho de 2017}

Atualmente o avanço no sensoriamento remoto, aliado ao desenvolvimento e/ou aprimoramento teórico-metodológicos, tem sido indispensáveis nos estudos da ciência sobre a superfície terrestre (BARBOSA e DORIGON, 2014).

O imageamento terrestre a partir de satélites permite a aquisição de informações sobre objetos sem contato físico direto, utilizando-se de sensores para coletar a energia proveniente do objeto, convertêla em sinal possível de ser registrado e apresentá-lo em forma adequada à extração de informações (NOVO, 1989). Sendo assim, obtém-se uma visão sinóptica do terreno, possibilitando o entendimento do contexto espacial para mensurar impactos naturais e/ou antrópicos locais, além disso, uma grande e importante utilização do imageamento remoto de superfície é o monitoramento ou a comparação entre tempos distintos, ou seja, o acompanhamento histórico de mudanças na superfície do planeta (BARBOSA e DORIGON, 2014).

Atualmente existem vários satélites orbitais de imageamento de superfície em operação. Neste artigo será utilizada a série Landsat, que desde o seu lançamento, seus sensores já tinham a capacidade de coletar imagens separadas em bandas espectrais em formato digital. A série passou por inúmeras inovações até atingir os sensores Landsat 8 que tiveram grandes aprimoramentos em relação as resoluções radiométrica e espacial. Porém, o mais importante foi a manutenção da resolução temporal em 16 dias, possibilitando a oferta contínua de imagens, desde 1975 quando foi lançado o Landsat 2 até os dias de hoje com o Landsat 8.

Sendo assim, com a disponibilização dessas imagens de forma gratuita, com periodicidade desde a década de 1980 e com qualidade, os estudos de clima urbano que se utilizam de dados espectrais vem aumentando e se destacando nas últimas décadas.

Uma das principais aplicações do sensoriamento remoto no estudo de climas urbanos consiste em examinar relações entre a estrutura espacial dos padrões térmicos urbanos e as características da superfície urbana, além de permitir um maior grau de detalhamento e uma visão espacial das temperaturas da superfície de uma determinada região com o seu entorno. De acordo com Coltri (2006), um alvo da superfície terrestre recebe radiação eletromagnética proveniente do Sol e, dependendo da sua composição, cor, forma e propriedade, parte desta energia será refletida e outra absorvida. Deste modo, afirma-se que satélites com sensor infravermelho termal mensuram a radiação do topo da atmosfera, sendo que esta pode ser convertida em temperatura aparente da superfície.

Como explanado por Voogt e Oke (2002, p. 370), a termografia da superfície é de suma importância, uma vez que modula a temperatura das camadas mais baixas da atmosfera e revela as ilhas de calor urbanas.

The surfacetemperatureisof prime importancetothestudyofurbanclimatology. It modulatestheairtemperatureofthelowestlayersoftheurbanatmosphere, is central totheinternalclimatesofbuildingsandaffectstheenergyexchangesthataffectthecomfo 


\section{OS DESAFIOS DA GEOGRAFIA FÍSICA NA FRONTEIRA DO CONHECIMENTO Instituto de Geociências - Unicamp Campinas - SP \\ 28 de Junho à 02 de Julho de 2017}

rtofcitydwellers. Surfaceandatmosphericmodificationsduetourbanizationgenerally lead to a modifiedthermalclimatethatiswarmerthanthesurrounding nonurbanizedareas, particularlyatnight. Thisphenomenonistheurbanheatisland (UHI).

Neste sentido, o sensoriamento remoto urbano responde a variação do balanço de energia da superfície. A temperatura superficial é resultante da incorporação dos efeitos de radiação dos materiais encontrados nas cidades e de suas propriedades termodinâmicas (WENG, 2009). Ou seja, entende-se que a refletividade da superfície (ou albedo) depende da cobertura da terra. Neste sentido, fica claro a estreita relação entre a temperatura da superfície, o uso e cobertura da terra e a vegetação urbana, por isso o interesse em abordá-los em correlação direta.

Sendo assim, o objetivo principal deste artigo foi identificar a influência exercida pelos diferentes usos e coberturas da terra, ao longo dos anos, na estrutura térmica da superfície urbana de Paranavaí/PR.

\section{CARACTERÍSTICAS DA CIDADE ESTUDADA}

Paranavaí/PR é uma cidade de porte médio, localizada no Norte do estado do Paraná (Figura 1) e que de acordo com o censo de 2010 (IBGE) conta com uma população total de 81.590 habitantes, sendo que 77.728 vivem na cidade, ou seja, 95\% da população é urbana.

Figura 1- Localização do município de Paranavaí/PR

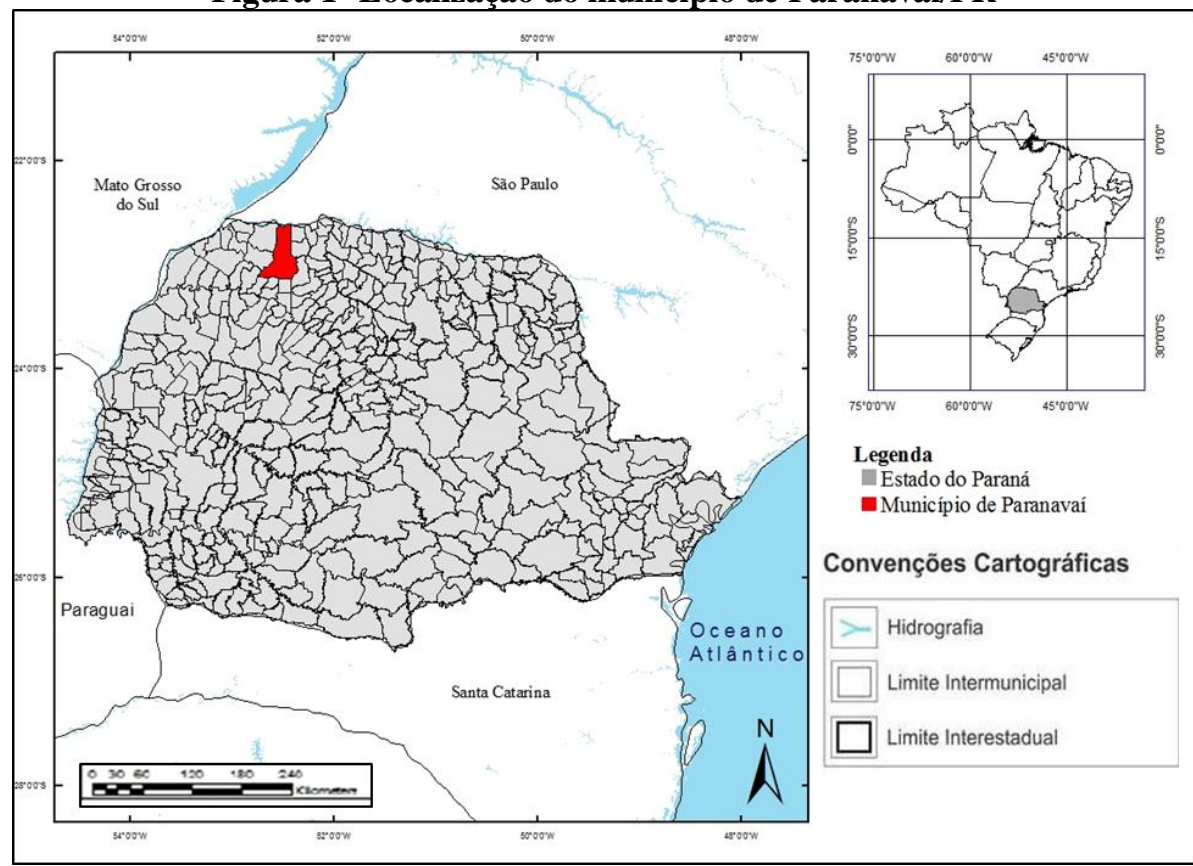

Elaboração: DORIGON, L. P., 2014

Paranavaí, assim como os principais municípios do Norte Paranaense, teve sua colonização instaurada pela empreiteira "Brazil Railway Company", através da sua subsidiária Braviaco - Companhia Brasileira de Viação e Comércio S/A, a qual obteve terras devolutas do governo e teve como obrigação construir vias e conglomerados urbanos, portanto, nesse início, a cidade foi planejada. 
O município foi instaurado em 1952, e a partir de então, nota-se uma evolução constante no aumento da população e no crescimento da malha urbana. Na década de 1950 teve início a proliferação dos loteamentos espontâneos nas direções leste, nordeste, sul e sudoeste da cidade. A maior expansão da malha urbana deu-se na década de 1960, impulsionada pela iniciativa de profundas mudanças na agricultura, resultando em uma expansão da cidade para todas as direções (BERNARDINO, 1999).

No início da década de 1970, sobre o comando dos militares, a atividade agropecuária nacional seguiu um modelo de modernização conservador que destinou todo o país a um intenso êxodo rural. $\mathrm{O}$ aumento populacional no ambiente urbano fez surgir "loteamentos de formas e tamanhos variados, que pela falta de critérios em relação ao planejamento global proporcionaram ao traçado urbano de Paranavaí uma aparência de "Colcha de Retalhos"” (CARGNIN, 2001, p.108). Na década de 1990, confirmou-se a migração rural-urbana e o município apresentou um crescimento populacional de $1,2 \%$.

Sendo assim, detecta-se que Paranavaí inicialmente teve a implantação de seu núcleo urbano seguindo as premissas de um planejamento elaborado para toda a região Noroeste do Paraná, no entanto, com o aumento da população houve a perda do controle dessa urbanização e novos loteamentos surgiram, sem necessariamente, seguir as diretrizes do plano inicial.

\section{MATERIAIS E MÉTODO}

Para a elaboração das cartas de temperatura da superfície, o cálculo do Índice de Vegetação Normalizado (NDVI) - que foi o índice selecionado para expressar a vegetação urbana - e as cartas de uso e cobertura da terra de Paranavaí foram utilizadas imagens dos satélites Landsat 7 e 8. Considerando que o objetivo maior da elaboração das cartas foi a comparação histórica, tornou-se necessário a realização da correção atmosférica, além de um procedimento que minimizasse o efeito dos elementos atmosféricos diários ou sazonais. Sendo assim, foi elaborada uma carta síntese anual para cada período escolhido.

Junto ao site do United StatesGeologicalSurvey/NASA (USGS) foi feita uma busca das imagens disponibilizadas e concluiu-se que os anos de 2002 (Landsat 7) e 2014/2013 (Landsat 8) seriam bons para representar Paranavaí, destacando que em 2014 foram utilizadas as imagens de janeiro, fevereiro e março e o restante, até completar um ano, selecionou-se imagens de 2013. A seguir (Quadro 1) apresentam-se as imagens e datas de aquisição e como pode ser observado, foi possível selecionar 10 imagens para cada época de análise.

Quadro 1- Data da aquisição das imagens utilizadas e seu respectivo sensor

\begin{tabular}{|c|c|}
\hline \multicolumn{2}{|c|}{ PARANAVAÍ } \\
\hline LANDSAT 7 (2002) & LANDSAT 8 (2013/2014) \\
\hline 12/Janeiro & 19/Janeiro/2014 \\
\hline 06/Fevereiro & 04/Fevereiro/2014 \\
\hline
\end{tabular}




\begin{tabular}{|c|c|}
\hline 12/Maio & 24/Março/2014 \\
\hline 28/Maio & $22 / \mathrm{Abril} / 2013$ \\
\hline 16/Agosto & $09 / J u n h o / 2013$ \\
\hline $17 /$ Setembro & $27 / J u l h o / 2013$ \\
\hline $03 /$ Outubro & $12 /$ Agosto/2013 \\
\hline $19 /$ Outubro & $28 /$ Agosto/2013 \\
\hline 04/Novembro & $13 /$ Setembro/2013 \\
\hline 20/Novembro & $18 /$ Dezembro/2013 \\
\hline
\end{tabular}

A correção atmosférica das bandas do infravermelho próximo e do vermelho, utilizadas para o cálculo do NDVI foi realizada no aplicativo IDRISI Andes 15.01 no módulo ATMOSC com o modelo Cos (t). Este modelo assume a irradiância como sendo 0,0; a transmitância é estimada a partir do cosseno do ângulo solar zenital e a reflectância é presumida a partir do valor de DN de objetos escuros, como corpos d'água e mata densa. Enquanto que esta correção para a banda do infravermelho termal, utilizada para a elaboração da carta de temperatura da superfície, ocorreu ao longo do processamento da imagem, através do logaritmo disponibilizado pela NASA, denominado AtmosphericCorrectionParameterCalculator2.

Com o pré-processamento pronto partiu-se para a elaboração das cartas. As imagens termais foram processadas no aplicativoArcMap, adicionando a correção atmosférica. Os sensores LandsatEnhancedThematicMapper Plus (ETM+) e Thermal Infrared Sensor (TIRS) adquirem dados de temperatura e armazenam essas informações como um número digital (DN) com um intervalo entre 0 $255(\mathrm{ETM}+)$ e 0 - 65535 (TIRS). É possível converter esses DNs em graus Celsius usando dois ou, opcionalmente, três passos.

O primeiro passo é a conversão dos valores de DN para radiância através de parâmetros fixos disponibilizados pela NASA. O segundo, opcional, é a aplicação da correção atmosférica que se utiliza de dados de superfície locais para obtenção de vários parâmetros e calculada com a AtmosphericCorrectionParameterCalculator. Após estes passos, calcula-se a temperatura da superfície em Kelvin, através da transformação da radiância para temperatura e finalmente, subtrai-se 273.15 da imagem para que o resultado seja obtido em graus Celsius. Vale destacar que os parâmetros de conversão e processamento das imagens são todos obtidos junto ao site da NASA ou no Handbook3 do Landsat 7.

Já o NDVI foi elaborado no aplicativoArcMaputilizando as bandas do vermelho (banda 3 para o Landsat 7 e banda 4 para o Landsat 8) e do infravermelho próximo (banda 4 para o Landsat 7 e banda 5 para o Landsat 8) das mesmas imagens supracitadas. O primeiro passo realizado foi a correção atmosférica das imagens de acordo com o citado a cima. As imagens corrigidas foram exportadas para o ArcMap e então, aplicou-se a fórmula:

\footnotetext{
${ }^{1}$ Idrisi é domínio da Clark Labs

${ }^{2}$ http://atmcorr.gsfc.nasa.gov/

${ }^{3}$ http://landsathandbook.gsfc.nasa.gov/pdfs/Landsat7_Handbook.pdf, acess Abril 23, 2012
} 


\section{OS DESAFIOS DA GEOGRAFIA FÍSICA NA FRONTEIRA DO CONHECIMENTO Instituto de Geociências - Unicamp \\ Campinas - SP \\ 28 de Junho à 02 de Julho de 2017}

\section{NDVI $=(p I V P-p V) /(p I V P+p V)$}

Onde,

NDVI: Índice de Vegetação Normalizada;

pIVP= Reflectância no infravermelho próximo;

$\mathrm{pV}=$ Reflectância no vermelho.

A aplicação desta fórmula faz com que a vegetação na imagem seja evidenciada com valores próximos a +1 , enquanto que a não presença de vegetação ou vegetação com características de estresse hídrico sejam apresentadas com valores próximos a -1 .

As cartas de uso e cobertura da terra foram elaboradas no aplicativo eCognitionDeveloper4 a partir de imagens Landsat 7 e 8 utilizando processos de segmentação e classificação supervisionada. De acordo com as características detectadas foram criadas as classes de uso e cobertura para a cidade e depois de concluída a classificação, os polígonos foram exportados para o ArcMapa fim de proceder a organização do layout final.

Para detalhar a análise da influência dos diferentes usos e coberturas da terra na termografia da superfície de Paranavaí, além da apresentação das cartas completas, selecionou-se um ponto específico para aprofundar a discussão, abordando diretamente questões relacionadas à estruturação urbana.

\section{RESULTADOS E DISCUSSÃO}

As figuras 2, 3 e 4 expõem as cartas de cada período selecionado e nelas verifica-se que, aparentemente, em 2014 pode ser entendido como menos quente e mais seco, uma vez que as temperaturas amenas são a maioria na carta de temperatura da superfície e as classes que se caracterizam por menor presença de vegetação ou menos umidade no solo são evidentes no NDVI. Entretanto, este fato ocorreu, sobretudo, em decorrência da diferenciação da distribuição das chuvas e da imagem utilizada para o que se refere ao NDVI e a distinta resolução espacial das imagens no tocante a temperatura da superfície.

\footnotetext{
${ }^{4}$ eCognitionDeveloper é domínio da Trimble
} 


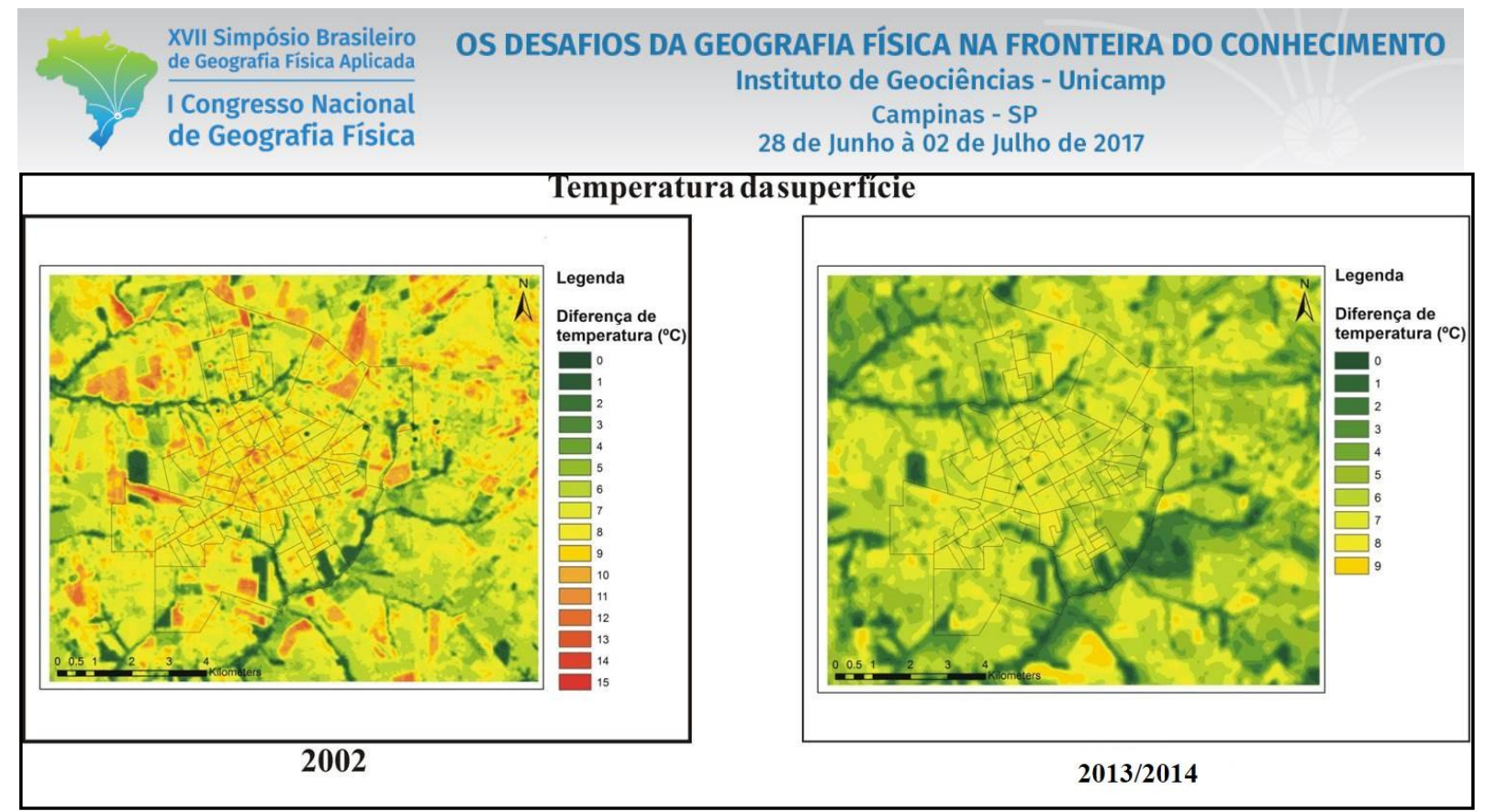

Figura 2: Cartas de temperatura da superfície de 2002 e 2013/2014

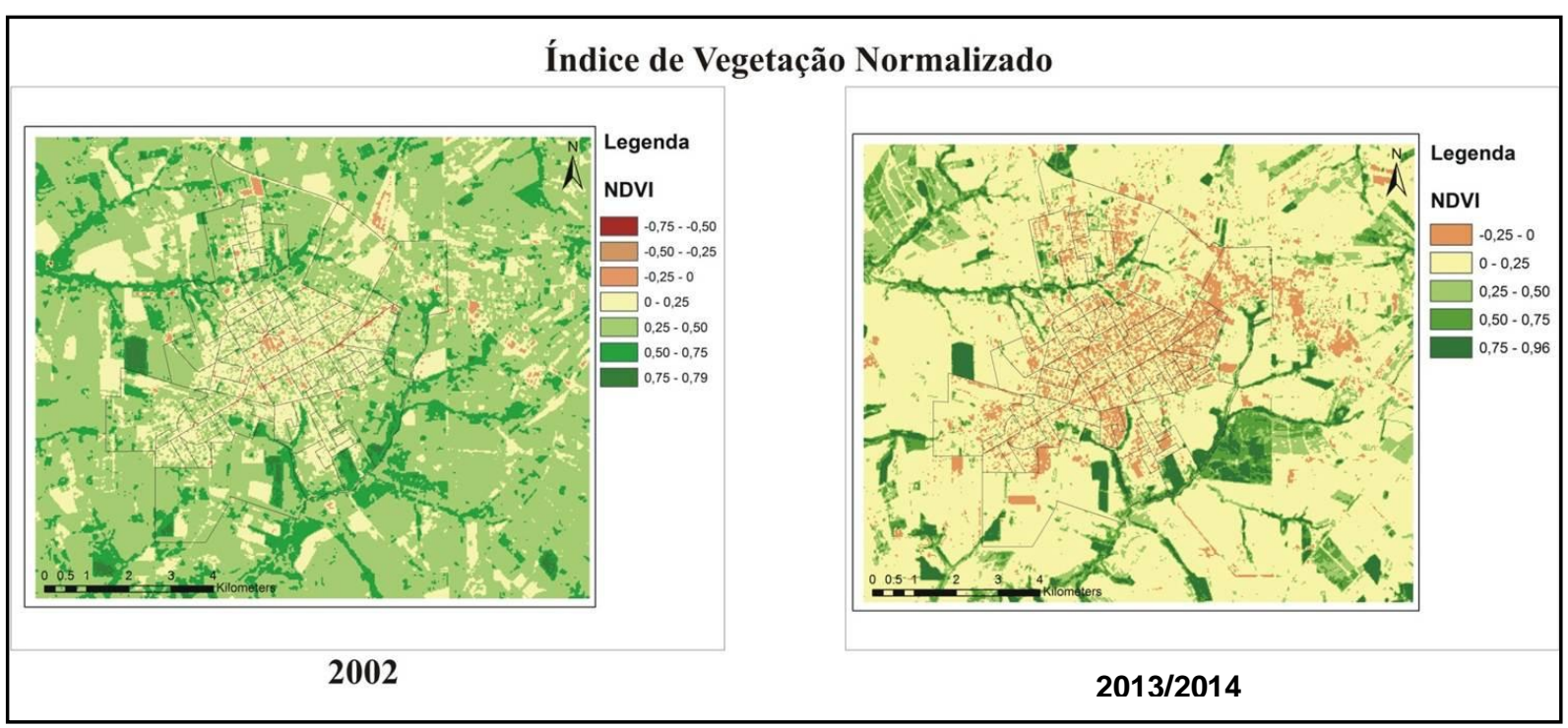

Figura 3: Cartas de NDVI de 2002 e 2013/2014

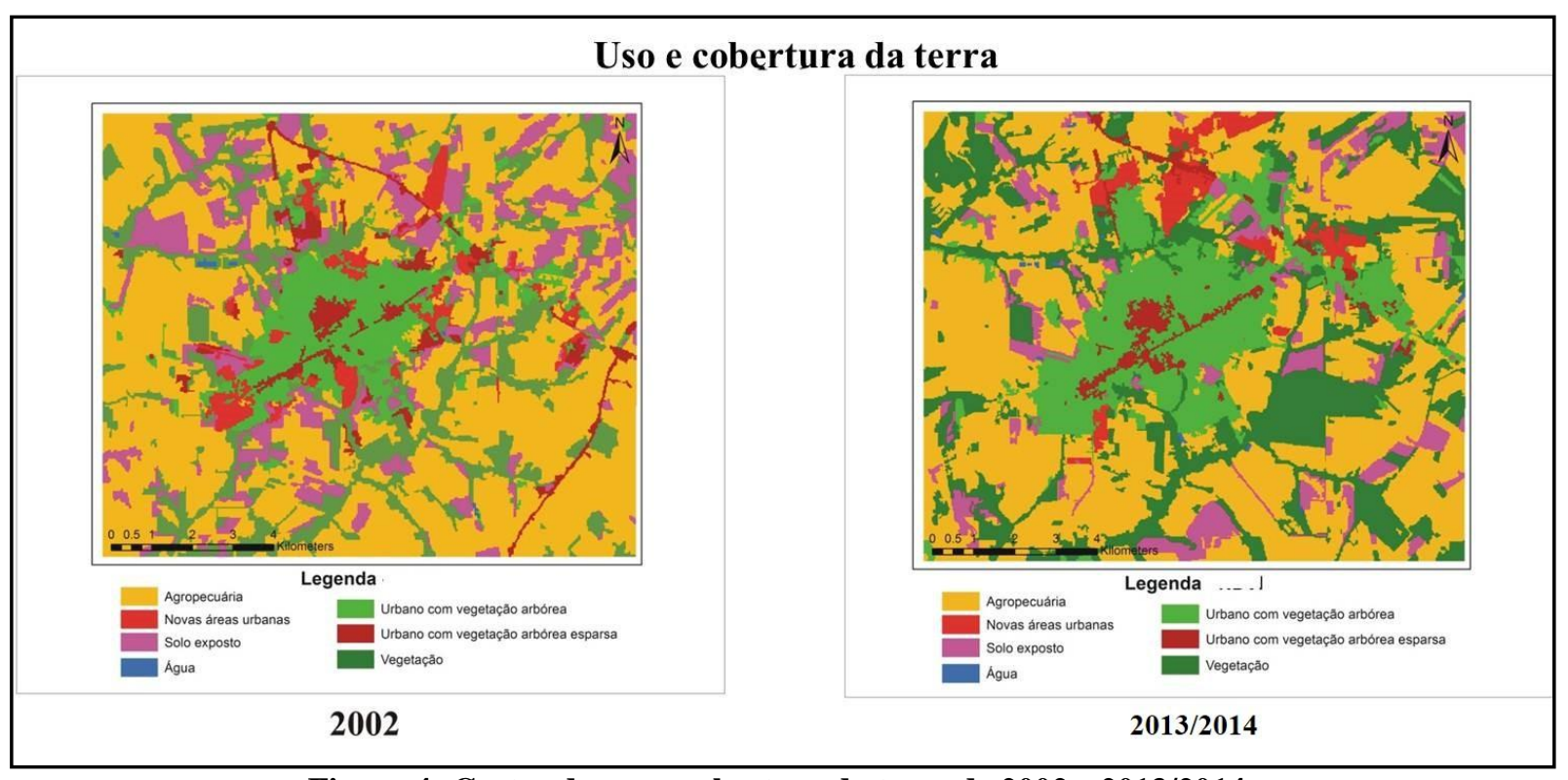

Figura 4: Cartas de uso e cobertura da terra de 2002 e 2013/2014

DOI - 10.20396/sbgfa.v1i2017.2382 - ISBN 978-85-85369-16-3 
As cartas de uso e cobertura da terra também sofreram influência da utilização de dois sensores diferentes, principalmente no que se refere à resolução radiométrica. As imagens do satélite Landsat 8 são obtidas com 16 bits, enquanto as do Landsat 7 com 8 bits, ou seja, os detalhes são melhores observados nas imagens captadas pelo novo sensor, por isso a segmentação e a classificação utilizadas se diferenciaram, porém em proporções muito pequenas, não afetando diretamente o trabalho.

Ao adentrar o espaço urbano de Paranavaí, notou-se que a área central e suas proximidades não apresentaram mudanças significativas nos 3 atributos, ou seja, estas localizações são espaços consolidados e evidenciaram os mesmos padrões: usos e coberturas baseados nas classes "urbano com vegetação arbórea" nas proximidades do centro e "urbano com vegetação arbórea esparsa" no centro da cidade; diferenças de temperaturas da superfície próximas as máximas encontradas em cada carta, com destaque ao triângulo central formado pelo encontro de grandes avenidas e caracterizado pelo adensamento comercial; e NDVI com valores que revelam menores quantidade de vegetação se comparados ao restante da cidade.

Já a periferia apresentou as maiores distinções nas três cartas quando comparados os dois períodos, em consequência da expansão urbana baseada principalmente na criação de empreendimentos habitacional.

Segundo Nalesso e Felix (2011) a Prefeitura Municipal de Paranavaí, a fim de sanar parte da demanda habitacional existente firmou parceria com a Companhia de Habitação do Paraná (COHAPAR) em conjunto com a Caixa Econômica Federal e implementaram seis empreendimentos de habitação popular na cidade entre 1999 e 2002. O financiamento ocorreu através de hipoteca para as famílias com renda entre 3 e 5 salários mínimos e caução para as famílias que comprovassem até um salário mínimo. Não somente na periferia foram implantados loteamentos, pois estes também surgiram nas proximidades do centro, porém em menor magnitude. O total de construções foi de 422 unidades habitacionais que se localizaram no Jardim São Jorge, Jardim Morumbi, Vila Operária e distritos de Graciosa e Mandiocaba.

Além das habitações sociais, Paranavaí também vem recebendo muitos incentivos privados e novos loteamentos particulares surgem a cada ano. Atribui-se isto ao crescimento da importância das cidades médias na rede urbana brasileira, que são procuradas por possuírem praticamente todos os serviços necessários à população e especificamente, em Paranavaí, a contribuição da indústria de beneficiamento da laranja e as granjas e avícolas são, atualmente, as duas grandes atividades que impulsionam o crescimento do município.

Neste sentido, devido à instabilidade e as fragilidades detectadas nas imagens que dificultaram as comparações, além da possibilidade de correlação com dados de estruturação urbana, é exibido na sequência um recorte específico que se destacou nas cartas, relacionado à implantação de um novo loteamento urbano (Figura 5). 
A área selecionada neste recorte (Ponto 1) encontra-se na porção nordeste da malha urbana de Paranavaí as margens da BR-376 e se refere a 3 loteamentos, o Jardim das Nações I e II e o Jardim Oasis. De acordo com o Plano Diretor (2008) do município, especificamente na planilha Loteamento por data de aprovação, os bairros Jardim das Nações I e II foram aprovados em 25/10/2002 e o Jardim Oasis em 20/10/2004.

Ainda como consta no Plano Diretor e através de informações obtidas junto ao Gerente da Divisão de Controle Urbano, os novos loteamentos em Paranavaí, após aprovação, são liberados para início da implementação de infraestrutura urbana. Basicamente são exigidos o saneamento básico (abastecimento de água e coleta e destinação de esgoto e resíduos sólidos), iluminação pública, asfaltamento e arborização urbana.

Com a infraestrutura concluída, as empreiteiras requerem à Prefeitura o alvará de liberação para dar início à comercialização dos lotes e se estiver tudo correto, esta concede o Alvará de Construção e o Habite-se.

De acordo com o site da empreiteira (Loteamentos Orcello Ltda.), esse loteamento surgiu após a compra de um antigo haras da cidade e em 2009, com toda a infraestrutura implantada começou a ser disponibilizado ao público interessado. O total é de 1690 terrenos, inicialmente todos com 15 metros de frente e 41 metros de comprimento, no entanto, devido à dificuldade de comercialização, os primeiros lotes vendidos foram diminuídos, a fim de minimizar os custos e otimizar as vendas.

Na figura 5 estão dispostas as informações referentes à termografia da superfície, a vegetação local e as classes de uso e cobertura da terra dos dois períodos possibilitando a análise comparativa.

Este recorte, com o passar de 13 anos apresentou maiores temperaturas da superfície local. Em 2002, a prevalência era de diferenças de temperaturas entre $6^{\circ} \mathrm{C} \mathrm{e} 7^{\circ} \mathrm{C}$, sendo que devido à presença da rodovia e de uma área significativa de solo exposto (solo e asfalto absorvem muito calor) o histograma apresentou maior frequência em $9^{\circ} \mathrm{C}$, porém destaca-se que a segunda maior classe de ocorrência foi a de $6^{\circ} \mathrm{C}$. Já em 2014 a imagem revelou que esse valor aumentou em praticamente $2^{\circ} \mathrm{C}$, tendo predominância entre $8^{\circ} \mathrm{C}$ e $9^{\circ} \mathrm{C}$ e mais uma vez o histograma apresentou maior frequência em outras diferenças de temperatura, dessa vez em $7^{\circ} \mathrm{C}$. Contudo, o mais importante a se destacar é a existência de dois pontos com valores de $9^{\circ} \mathrm{C}$, fato que não ocorreu no local na carta de 2002.

As cartas de NDVI, utilizadas para detectar a presença ou não de vegetação, apresentaram padrão inverso às cartas de temperatura da superfície, sendo que em 2002 ficou evidente a existência de vegetação no local com expressiva superioridade das classes $0,25-0,50$ e $0,50-0,75$, enquanto que no histograma de 2014 a maior frequência detectada foi de 0 - 0,25 e é possível observar na imagem a presença relevante de pontos pertencentes à classe $-0,25-0$, que é caracterizada pela quase total ausência vegetacional. 
No tocante as cartas de uso e cobertura da terra destaca-se que em 2002 não existia a classe "Novas áreas urbanas" e a predominante, com 2,35km2, era a classe "Agropecuária". Já em 2014 a classe "Novas áreas urbanas" foi identificada e ainda como sendo a de maior extensão (1,31 km2). 

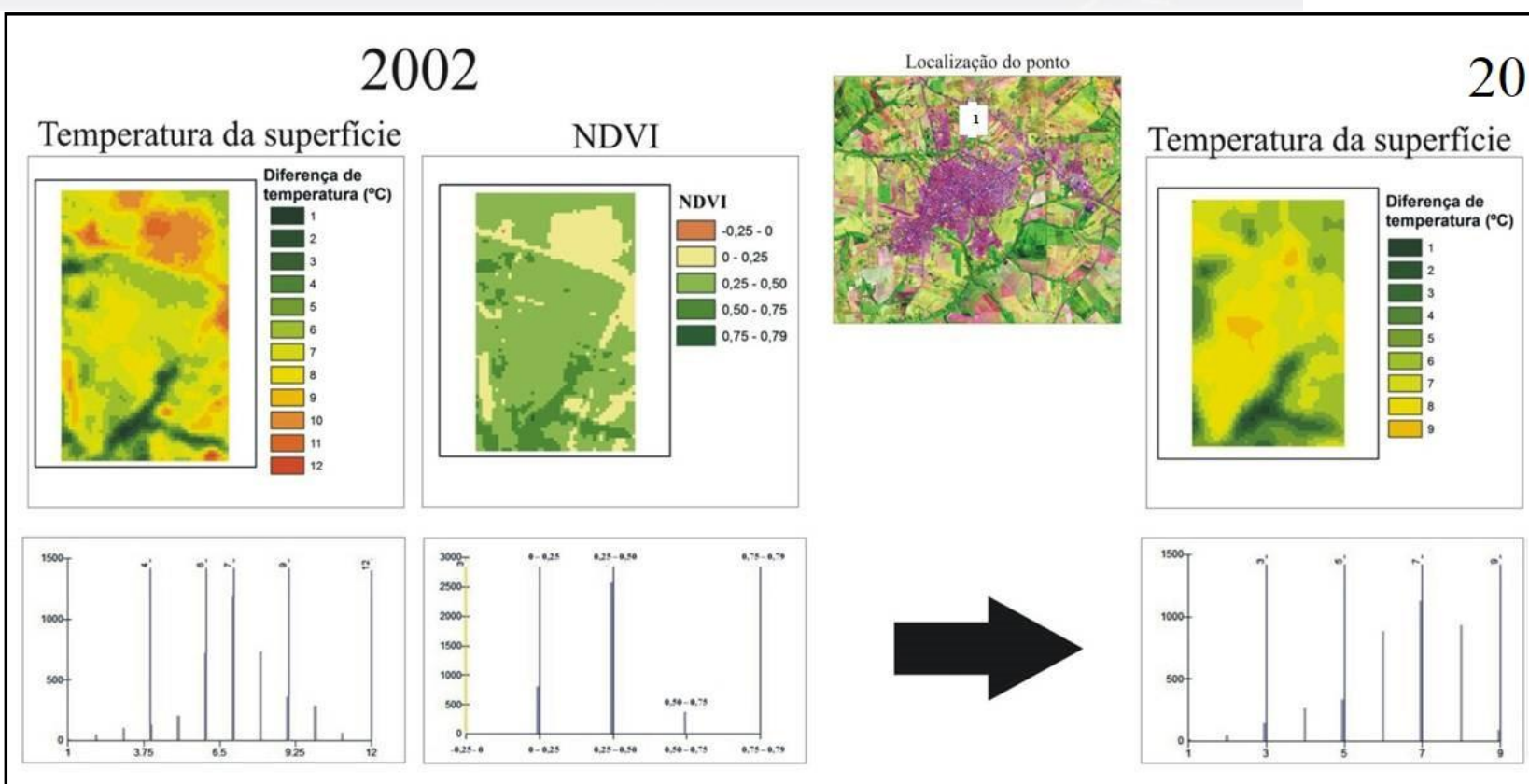

$2013 / 2014$

NDVI
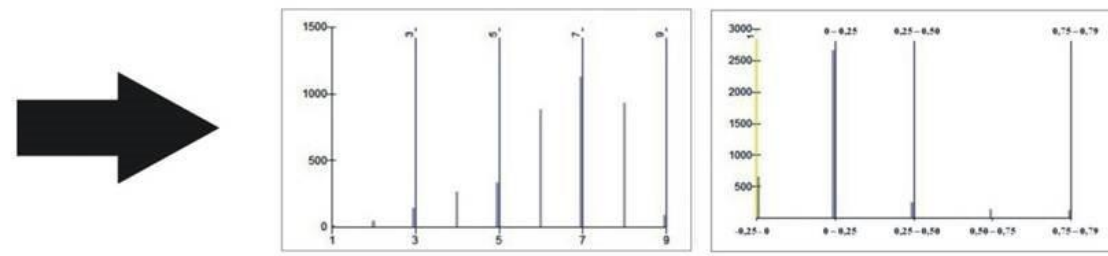

Uso e cobertura da terra

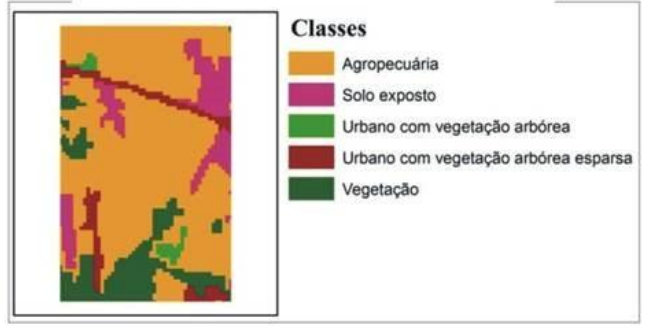

Uso e cobertura da terra

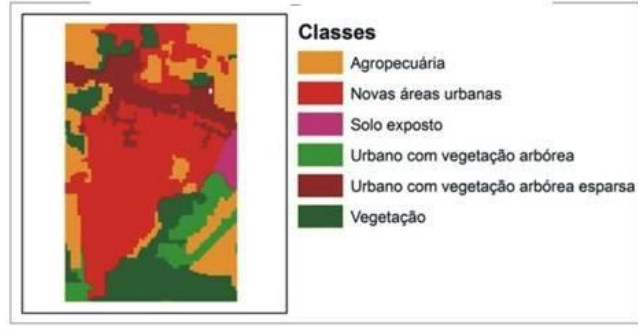

\begin{tabular}{|l|r|}
\hline \multicolumn{1}{|c|}{ Classes } & Área (Km2) \\
\hline Agropecuária & 2.35 \\
\hline Solo exposto & 0.37 \\
\hline Urbano com vegetação arbórea & 0.06 \\
\hline Urbano com vegetação arbórea esparsa & 0.2 \\
\hline Vegetação & 0.47 \\
\hline
\end{tabular}

\begin{tabular}{|l|r|}
\hline \multicolumn{1}{|c|}{ Classes } & Área (Km2) \\
\hline Agropecuária & 0.79 \\
\hline Novas áreas urbanas & 1.31 \\
\hline Solo exposto & 0.06 \\
\hline Urbano com vegetação arbórea & 0.25 \\
\hline Urbano com vegetação arbórea esparsa & 0.39 \\
\hline Vegetação & 0.64 \\
\hline
\end{tabular}

Figura 5:Recortes históricos das cartas de temperatura da superfície, NDVI e uso e cobertura da terra do Jardim Oasis, Jardim das Nações I e Jardim das Nações II

DOI - 10.20396/sbgfa.v1i2017.2382 - ISBN 978-85-85369-16-3 
XVII Simpósio Brasileiro

de Geografia Fisica Aplicada

I Congresso Nacional

de Geografia Física
OS DESAFIOS DA GEOGRAFIA FÍSICA NA FRONTEIRA DO CONHECIMENTO

Instituto de Geociências - Unicamp

Campinas - SP

28 de Junho à 02 de Julho de 2017

Neste sentido, essa área obteve seu destaque devido à transformação pela qual passou, uma vez que nas imagens de 2002 ainda era ocupada por um haras que contava com vegetação em praticamente a totalidade de seu território e a partir de 2009 começou ali a construção e instalação de equipamentos de infraestrutura urbana e o loteamento do local, deixando o solo exposto, além de implantar cobertura asfáltica, elementos que elevam a temperatura da superfície.

\section{CONSIDERAÇÕES FINAIS}

O sensoriamento remoto da superfície através da temperatura da superfície, NDVI e uso e cobertura da terra revelou, em partes, algumas características climáticas e urbanas de Paranavaí,em especial a relação entre a temperatura da superfície e a presença ou falta de vegetação. A importância da vegetação de porte arbóreo com copas largas também foi verificada na análise do crescimento urbano e as diferenças na temperatura da superfície. Para essa análise foram elaboradas cartas de temperatura da superfície, NDVI e uso da terra a fim de cumprir a segunda parte do objetivo proposto para esse trabalho.

$\mathrm{Na}$ tentativa de analisar as cartas históricas geradas houve a necessidade de melhor entender o planejamento e a estrutura urbana de Paranavaí e, após a apreciação da legislação e histórico municipal, concluiu-se que essencialmente a supressão da vegetação para a implantação de materiais construtivos altera a temperatura da superfície, elevando-a.

Os resultados obtidos com as cartas de 2002 e 2014 revelaram exatamente este fator, pois o recorte, que inicialmente (2002) estava inserido na classe "Agropecuária" apresentou valores de temperatura da superfície mais amenos e valores médios de NDVI. Entretanto, nas cartas posteriores, de 2014, devido a implementação do novo loteamento, ou seja, a substituição de vegetação por material construtivo, foram registrados maiores valores de termografia da superfície e menores índices de vegetação, sendo portanto, esta área incluída na classe "Novas áreas urbanas".

Vale destacar a importância da ferramenta do sensoriamento remoto no entendimento do clima urbano como fenômeno contínuo e em relação a outros condicionantes encontrados nas cidades. Através do imageamento de superfície é possível o entendimento da temperatura urbana ao longo de toda a malha. Sabe-se que o clima diferenciado das cidades é condicionado, principalmente pelos diferentes usos e coberturas da terra, sendo as árvores grandes aliadas na diminuição do calor. Neste contexto, confirmou-se que a utilização de imagens de satélite podem e devem ser empregadas como ótimas ferramentas para essas análises, uma vez que além do clima, obtêm-se informações do terreno, possibilitando correlações diretas e indiretas. 


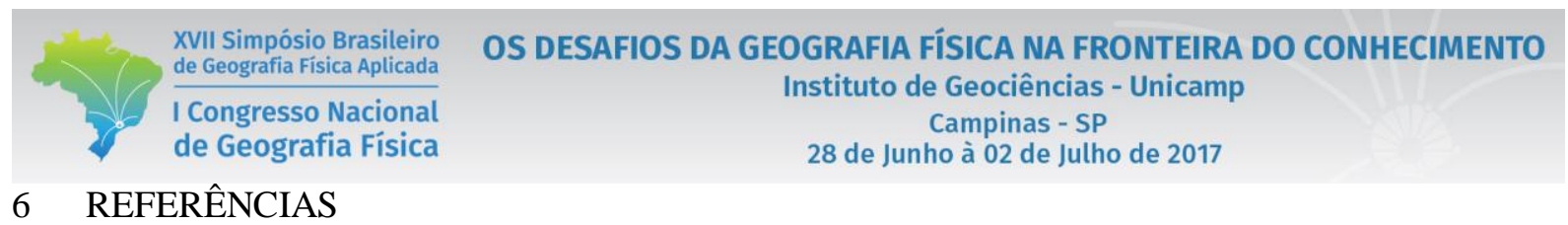

\section{REFERÊNCIAS}

AMORIM, M. C. de C. T.. O Clima urbano de Presidente Prudente/SP. Tese (doutorado) FFLCH-USP, 2000.

BARBOSA, Liriane G.; DORIGON, L. P.. Análise temporal da cobertura vegetal no município de Teresina/PI a partir da aplicação de NDVI. In: XXVI Congresso Brasileiro de Cartografia, V Congresso Brasileiro de Geoprocessamento e XXV Exposicarta, 2014, Gramado-RS. XXVI CBC 2014, 2014. v. 26. p. 01-12.

BERnARDINO. V. M. P.. Processo de ocupação do município de Paranavaí: A mobilidade da força de trabalho e a sua redistribuição espacial. (Tese de Mestrado apresentada ao conselho de Curso de Pós-Graduação em Geografia/FCT-UNESP). Presidente Prudente, 1999.

CARGNIN, R. C. N.. Vila Alta: concentração da pobreza urbana em um espaço periférico de Paranavaí. (DIssertação de Mestrado apresentada ao conselho de Curso de Pós-Graduação em Geografia/FCT-UNESP). Presidente Prudente, 2001.

COLTRI, P. P. et. al. Ilhas de Calor da estação de inverno da área urbana do município

de Piracicaba, SP. In: XIII Simpósio Brasileiro de Sensoriamento Remoto, 2007.

Florianópolis, CD-ROM.

LIMA, Valéria; AMORIM, Margarete C. C. T. . A utilização de informações de temperatura da superfície, do NDVI e de temperatura do ar na análise de qualidade ambiental urbana. In: XV SIMPÓSIO BRASILEIRO DE SENSORIAMENTO REMOTO, 2011, Curitiba/PR. Anais XV Simpósio Brasileiro de Sensoriamento Remoto SBSR, Curitiba, PR. São José dos Campos: MCT/INPE, 2011. p. 1028-1035.

NALESSO, A. P. P.; LOURIVAL S. F.. A conformação histórica das classes sociais no capitalista: uma aproximação acerca das condições de vida da classe trabalhadora no século XIX, na Inglaterra. In: II encontro de iniciação cientifica da FAFIPA, 2011, Paranavaí. Anais do II Encontro de Iniciação Cientifica da FAFIPA. Paranavaí: FAFIPA, 2011. v. 1. p. 01.

NOVO, E. M. L. M. Sensoriamento Remoto: Princípios e Aplicações.. 2. ed. São Paulo: Edgard Blucher, 1989. v. 2000. $269 \mathrm{p}$.

VOOGT, J.; OKE, T. R.;.Thermalremotesensingofurbanclimates. Remote SensingofEnvironment, v. 86, p. 370$384,2003$.

WENG, Q.. Thermalinfraredremotesensingofurbanclimateandenvironmentalstudies: Methods, applications, andtrends. ISPRS JournalofPhotogrammetryand Remote Sensing, v. 64, p. 335-344, 2003. 